\title{
PENGARUH SENAM LANSIA TERHADAP PERUBAHAN NYERI SENDI PADA LANSIA DI BALAI SOSIAL LANJUT USIA (BSLU) MANDALIKA MATARAM
}

\author{
Febriati Astuti ${ }^{1}$, Eva Marvia $^{2}$, Sri Nurjanah Wulandari ${ }^{3}$ \\ ${ }^{1,2)}$ Pengajar Sekolah Tinggi Ilmu Kesehatan (STIKES) Mataram \\ Email: putrasuryadi88@gmail.com
}

\begin{abstract}
ABSTRAK
Penuaan adalah suatu proses alami yang tidak dapat dihindari, berjalan secara terus-menerus dan berkesinambungan yang selanjutnya akan menyebabkan perubahan anatomis, fisiologis, dan biokimia pada tubuh, sehingga akan mempengaruhi fungsi dan kemampuan tubuh secara keseluruhan. Seiring perubahan usia, tanpa disadari juga pada orang lanjut usia akan mengalami perubahan-perubahan fisik, psikososial dan spiritual dimana salah satu perubahan tersebut adalah gangguan muskuloskeletal yaitu nyeri sendi. Nyeri sendi adalah suatu peradangan sendi yang ditandai dengan pembengkakan sendi, warna kemerahan, panas, nyeri dan terjadinya gangguan gerak. Pada keadaan ini lansia sangat terganggu, apabila lebih dari satu sendi yang terserang. Salah satu upaya untuk mengurangi nyeri sendi adalah senam lansia. Senam lansia adalah olahraga ringan yang mudah dilakukan dan tidak memberatkan, yang dapat diterapkan pada lansia. Aktivitas olahraga ini akan membantu tubuh lansia agar tetap bugar dan tetap segar karena senam lansia mampu melatih tulang tetap kuat, mendorong jantung bekerja secara optimal dan membantu menghilangkan radikal bebas yang berada di dalam tubuh. Penelitian ini bertujuan untuk mengetahui adanya perubahan nyeri sendi pada lansia di Balai Sosial Lanjut Usia (BSLU) Mandalika Mataram

Desain yang digunakan dalam penelitian ini adalah pra eksperimen dengan pendekatan one group pretest-posttest. Besar sampel sebanyak 31 responden dengan teknik sampling menggunakan purposive sampling. Pengumpulan data menggunakan obervasi dan wawancara. Analisa data yang digunakan yaitu uji paired t-test dengan tingkat kepercayaan sebesar 5\% atau 0,05. Hasil uji statistik diperoleh hasil $p$-value $=$ 0,000 lebih kecil dari nilai signifikan 0,05 sehingga Ho ditolak dan Ha diterima, yang artinya ada pengaruh perubahan nyeri sendi sebelum senam lansia dengan sesudah senam lansia.

Berdasarkan hasil penelitian ada pengaruh perubahan nyeri sendi sebelum senam lansia dengan sesudah senam lansia pada lansia di Balai Sosial Lanjut Usia (BSLU) Mandalika Mataram.
\end{abstract}

Kata Kunci : Lansia, Nyeri Sendi, Senam Lansia

\section{PENDAHULUAN}

Penuaan atau proses terjadinya tua adalah suatu proses menghilangnya secara perlahan-lahan kemampuan jaringan untuk memperbaiki diri atau mengganti dan mempertahankan fungsi normalnya sehingga tidak dapat bertahan terhadap infeksi serta memperbaiki kerusakan yang diderita (Maryam,dkk,2008). Penuaan adalah suatu proses alami yang tidak dapat dihindari, berjalan secara terus-menerus dan berkesinambungan. Selanjutnya akan menyebabkan perubahan anatomis, fisiologis, dan biokimia pada tubuh, sehingga akan mempengaruhi fungsi dan kemampuan tubuh secara keseluruhan (Maryam,2008). 
Seiring perubahan usia, tanpa disadari juga pada orang lanjut usia akan mengalami perubahan-perubahan fisik, psikososial dan spiritual. Salah satu perubahan tersebut adalah gangguan kardiovaskular dan muskuloskeletal. Selain gangguan kardiovaskuler yang diketahui dapat mengancam jiwa lansia, masalah muskuloskeletal terutama nyeri sendi.

Nyeri sendi adalah suatu peradangan sendi yang ditandai dengan pembengkakan sendi, warna kemerahan, panas, nyeri dan terjadinya gangguan gerak. Pada keadaan ini lansia sangat terganggu, apabila lebih dari satu sendi yang terserang (Handono, 2013). Upaya-upaya untuk mempertahankan kesehatan lansia baik yang bersifat perawatan, pengobatan, pola hidup sehat, diantaranya senam lansia (Widianti \& Proverawati,2010).

Berdasarkan hasil studi pendahuluan yang di lakukan di BSLU Mandalika Mataram bulan Oktober 2016, terdapat 76 lansia dan 61 lansia diantaranya mengidap nyeri sendi. Hasil wawancara dengan petugas panti bahwa banyak lansia yang tidak mengikuti senam lansia karena lansia merasa kesulitan untuk bergerak karena nyeri yang dirasakan padahal senam lansia sudah menjadi program rutin yang dilakukan di BSLU Mandalika Mataram

Senam lansia adalah olahraga ringan yang mudah dilakukan dan tidak memberatkan, yang dapat diterapkan pada lansia. Aktivitas olahraga ini akan membantu tubuh lansia agar tetap bugar dan tetap segar, karena senam lansia ini mampu melatih tulang tetap kuat, mendorong jantung bekerja secara optimal dan membantu menghilangkan radikal bebas yang berkeliaran didalam tubuh (Widianti \& Proverawati,2010).

Berdasarkan uraian fenomena dan latar belakang masalah yang dikemukakan maka peneliti tertarik untuk melakukan penelitian tentang apakah ada Pengaruh senam lansia terhadap perubahan nyeri sendi pada lansia.

\section{TUJUAN PENELITIAN}

Untuk mengetahui Pengaruh Senam Lansia Terhadap Perubahan Nyeri Sendi Pada Lansia Di BSLU Mandalika Mataram

\section{METODE PENELITIAN}

A. Populasi, Sampel dan Tehnik Sampling 1. Populasi

Populasi adalah wilayah generalisasi terdiri dari subjek dan objek yang mempunyai kualitas dan karakteristik tertentu yang ditetapkan oleh peneliti untuk dipelajari dan ditarik kesimpulannya (Sugiyono, 2016). Populasi dalam penelitian ini adalah semua lansia yang mengalami nyeri sendi sebanyak 61 orang.

2. Sampel dan Tehnik Sampling

Sampel adalah sebagian atau wakil populasi yang diteliti (Arikunto, 2013).

Teknik sampling yang digunakan adalah purposive sampling, dimana sampel diambil berdasarkan pada suatu pertimbangan tertentu yang dibuat oleh peneliti sendiri berdasarkan kriteria inklusi dan eksklusi. Jumlah sampel 31 orang.

\section{B. Rancangan Penelitian}

Rancangan penelitian yang digunakan dalam penelitian ini adalah praeksperimen

\section{Tehnik Pengumpulan Data}

\section{Instrumen Penelitian}

Instrumen penelitian adalah alat atau fasilitas yang digunakan oleh peneliti dalam mengumpulkan data agar pekerjaannya lebih mudah dan hasilnya lebih baik, dalam arti 
lebih cermat, lengkap dan sistematis sehingga lebih mudah diolah (Arikunto, 2013). Instrumen yang digunakan dalam penelitian ini adalah dengan menggunakan Mankoski pain scale dan wongbaker faces

2. Tehnik Pengumpulan Data

Pengumpulan data pada penelitian ini dilakukan dengan cara observasi dan wawancara secara langsung kepada responden

D. Analisa Data

Berdasarkan tujuan penelitian maka tekhnik analisa data dalam penelitian ini menggunakan uji paired t-test

\section{HASIL DAN PEMBAHASAN}

A. HASIL PENELITIAN

1. Identifikasi Perubahan Nyeri Sendi Sebelum diberikan Senam Lansia

\begin{tabular}{|c|c|c|c|}
\hline No. & Nyeri Sendi & Frekuensi & $\begin{array}{c}\text { Presentase } \\
(\%)\end{array}$ \\
\hline 1. & Ringan & 11 & 35,49 \\
\hline 2. & Sedang & 20 & 64,51 \\
\hline \multicolumn{2}{|c|}{ Total } & 31 & 100 \\
\hline
\end{tabular}

Sumber: Data primer

Tabel di atas menunjukkan bahwa sebelum diberikan senam lansia responden sebagian besar mempunyai nyeri sedang sebanyak 20 orang $(64,51 \%)$ dan nyeri ringan sebanyak 11 orang $(35,49 \%)$.

2. Identifikasi Perubahan Nyeri Sendi Setelah diberikan Senam Lansia

\begin{tabular}{|c|c|c|c|}
\hline No. & $\begin{array}{c}\text { Nyeri } \\
\text { Sendi }\end{array}$ & Frekuensi & $\begin{array}{c}\text { Persentase } \\
(\%)\end{array}$ \\
\hline 1. & $\begin{array}{c}\text { Tidak } \\
\text { Nyeri }\end{array}$ & 1 & 3,22 \\
\hline 2. & Ringan & 20 & 64,51 \\
\hline 3. & Sedang & 10 & 32,26 \\
\hline \multicolumn{2}{|c|}{ Total } & 31 & 100 \\
\hline
\end{tabular}

Sumber : Data primer

Tabel di atas menunjukkan bahwa setelah diberikan senam lansia didapatkan tidak nyeri sebanyak 1 orang $(3,22 \%)$, nyeri ringan sebanyak 20 orang $(64,51 \%)$ dan nyeri sedang sebanyak 10 orang $(32,26 \%)$.

3. Analisa Pengaruh Senam Lansia Terhadap Perubahan Nyeri Sendi pada Lansia

\begin{tabular}{|l|l|l|l|l|l|}
\hline $\begin{array}{l}\mathrm{t}- \\
\text { hitun } \\
\mathrm{g}\end{array}$ & $\begin{array}{l}\mathrm{t}- \\
\text { tabel }\end{array}$ & $\begin{array}{l}\text { Mean } \\
\text { preste } \\
\text { st }\end{array}$ & $\begin{array}{l}\text { Mean } \\
\text { postte } \\
\text { st }\end{array}$ & $\begin{array}{l}\text { Bed } \\
\mathrm{a} \\
\text { mea } \\
\mathrm{n}\end{array}$ & interpretasi \\
\hline 7,33 & $\begin{array}{l}2,04 \\
0\end{array}$ & 4,094 & 3,216 & 0,88 & $\begin{array}{l}\text { t-hitung > } \\
\text { t-tabel } \\
(7,33>2,04 \\
0) \text { maka } \\
\text { Ho ditolak } \\
\text { dan Ha } \\
\text { diterima }\end{array}$ \\
\hline
\end{tabular}

Sumber: Data Primer

\begin{tabular}{|c|c|c|c|c|c|c|c|}
\hline \multicolumn{5}{|c|}{ Paired differences } & \multirow[t]{3}{*}{$\mathrm{T}$} & \multirow[t]{3}{*}{ Df } & \multirow[t]{3}{*}{ Sig. } \\
\hline \multirow[t]{2}{*}{ Mean } & \multirow[t]{2}{*}{ Std.dev } & \multirow[t]{2}{*}{$\begin{array}{l}\text { Std.error } \\
\text { mean }\end{array}$} & \multicolumn{2}{|c|}{$\begin{array}{l}95 \% \\
\text { confidence } \\
\text { interval the } \\
\text { difference }\end{array}$} & & & \\
\hline & & & $\begin{array}{l}\text { Lowe } \\
\mathrm{r}\end{array}$ & $\begin{array}{l}\text { Up } \\
\text { per }\end{array}$ & & & \\
\hline $\begin{array}{l}0.875 \\
00\end{array}$ & 0.70711 & 0.12500 & $\begin{array}{l}0.620 \\
06\end{array}$ & $\begin{array}{l}1.1 \\
299 \\
4\end{array}$ & $\begin{array}{l}7.0 \\
00 \\
0\end{array}$ & 31 & 0.000 \\
\hline
\end{tabular}

Sumber: Data primer

Tabel di atas menunjukkan bahwa nilai beda mean pretest dan posttest sebesar 0,88. Dimana $\mathrm{t}$ hitung $=7,33>\mathrm{t}$-tabel $=2,040$ yang artinya

4. Hasil pengujian Hipotesis

Dengan menggunakan uji statistik paired t-test didapatkan $\mathrm{p}$ value dengan nilai 0,000 sehingga H0 ditolak, maka dapat disimpulkan ada pengaruh senam lansia terhadap perubahan nyeri sendi pada lansia.

\section{B. PEMBAHASAN}

Merujuk pada tujuan umum penelitian yakni untuk mengetahui pengaruh senam lansia terhadap perubahan nyeri sendi pada lansia dengan jumlah sampel sebanyak 31 responden

1. Perubahan nyeri sendi sebelum diberikan senam lansia

Berdasarkan hasil penelitian dari 31 responden sebelum diberikan senam lansia didapatkan 
bahwa sebagian responden masuk dalam kategori nyeri sedang sebanyak $20 \quad(64,51 \%)$ responden dan nyeri ringan sebanyak 11 $(35,49 \%)$ responden.

Penuaan adalah suatu proses alami yang tidak dapat dihindari, berjalan secara terus-menerus dan berkesinambungan. Selanjutnya akan menyebabkan perubahan anatomis, fisiologis, dan biokimia pada tubuh, sehingga akan mempengaruhi fungsi dan kemampuan tubuh secara keseluruhan (Maryam,2008).

Berdasarkan hasil penelitian dimana lebih dari setengah responden mengalami nyeri dengan skala sedang. Menurut Potter \& Perry (2005) dalam fundamental keperawatan, yaitu terdapat kemungkinan yang berhubungan dengan tipe nyeri kronis pada daerah sendi tertentu, dimana dikatakan nyeri kronis bila klien sudah pernah merasakan nyeri sebelumnya dan berlangsung selama 6 bulan.

Cara lansia bereaksi terhadap nyeri dapat berbeda dengan cara bereaksi orang yang lebih muda. Karena individu lansia mempunyai metabolisme yang lebih lambat dan rasio lemak tubuh terhadap massa otot lebih besar dibanding individu berusia lebih muda, oleh karenanya analgesik dosis kecil mungkin cukup untuk menghilangkan nyeri pada lansia. Persepsi nyeri pada lansia mungkin berkurang sebagai akibat dari perubahan patologis berkaitan dengan beberapa penyakitnya (misalnya diabetes), akan tetapi pada individu lansia yang sehat persepsi nyeri mungkin tidak berubah (Le Mone \& Burke,2008).

2. Perubahan nyeri sendi setelah diberikan senam lansia
Berdasarkan hasil penelitian setelah diberikan senam lansia didapatkan bahwa terjadi perubahan nyeri sendi dengan kategori tidak nyeri $1(3,22 \%)$ responden, nyeri ringan $20(64,51 \%)$ responden dan nyeri sedang $10(32,26 \%)$ respoden.

Senam lansia dapat membantu tubuh tetap segar dan bugar karena senam lansia mampu melatih tulang tetap kuat (Anggriana,2010).

Menurut Indonesian Nursing (2008) senam lansia membuat peredaran darah lancar dan meningkatkan volume darah dan meningkatkan keseimbangan antara osteoblast dan osteoclast. Apabila senam terhenti maka pembentukan osteoblast berkurang sehingga pembentukan tulang berkurang dan dapat berakibat pengeroposan tulang. Maka dari itu melakukan senam lansia dengan rutin dapat menjaga tulang dan persendian tetap kuat.

Dari hasil penelitian juga didapatkan bahwa masih ada beberapa lansia yang masih dalam kategori nyeri sedang, hal ini dikarenakan beberapa lansia yang tidak mengikuti gerakan senam dengan baik kemudian dipengaruhi juga oleh factor usia dimana makin lama usia lansia maka metabolisme lebih lambat dan rasio lemak tubuh terhadap massa otot lebih besar dibanding lansia yang lebih muda, persepsi nyeri pun berkurang sebagai akibat dari perubahan psikologis berkaitan dengan penyakitnya (Stanley,2007).

3. Analisa pengaruh senam lansia terhadap perubahan nyeri sendi pada lansia.

Hasil uji statistic paired t-test diperoleh hasil hasil $p$ value sebesar 0,000 sehingga Ho ditolak dan Ha di terima yang artinya ada perbedaan tingkat nyeri sendi sebelum dan 
sesudah senam lansia yang berarti ada pengaruh senam lansia terhadap perubahan nyeri sendi pada lansia.

Senam lansia merupakan suatu latihan fisik yang mempunyai pengaruh yang baik untuk meningkatkan kemampuan otot sendi. Aktifitas fisik berupa senam dapat mengurangi sensasi nyeri pada persendian lebih baik daripada hanya dengan beristirahat (Mentes et al, 2010). Senam lansia dapat meningkatkan kecepatan metabolisme untuk memproduksi cairan synovial, sendi lebih fleksibel, gerakan lebih bebas, meningkatkan sirkulasi darah, meningkatkan mobilitas, dan meredakan nyeri.

Berdasarkan penelitian yang dilakukan sebelumnya oleh Bennel et al., (2012) menjelaskan aktivitas fisik dapat meningkatkan fungsional fisik lansia dan kualitas hidup lansia. Jika lansia enggan mengikuti kegiatan senam, justru dapat menyebabkan kekakuan tulang dan sendi yang menjadi penyebab timbulnya nyeri persendian pada lansia (Michael \& Kelley, 2010).

$$
\text { Pada dasarnya nyeri }
$$
persendian yang sering dikeluhkan oleh kebanyakan lansia merupakan hal yang biasa (fisiologis) namun jika nyeri dirasakan sampai mengganggu aktivitas bahkan istirahat lansia hal tersebut tidak bisa dibiarkan. Diperlukan tindakan untuk mengurangi nyeri tersebut, diantaranya dengan melakukan kebiasaan hidup sehat dan berolahraga (Stanley,2007).

Senam lansia selain mudah juga dapat dilakukan oleh semua lansia tanpa mengeluarkan biaya dan baik untuk melatih kekuatan otot dan manfaat lainnya melakukan senam secara teratur bagi lansia adalah mempertahankan atau meningkatkan taraf kesegaran jasmani yang baik, membentuk kondisi fisik (kekuatan otot, kelenturan, keseimbangan, ketahanan, keluwesan, dan kecepatan) dan memperlambat proses degenerasi karena perubahan usia (Maryam dkk, 2008).

\section{KESIMPULAN}

1. Sebelum diberikan senam lansia sebagian besar responden mengalami nyeri sedang sebanyak $20(64,51 \%)$ respoden dan nyeri ringan sebanyak 11 $(35,49 \%)$ respoden.

2. Setelah diberikan senam lansia,reponden yang tidak nyeri sebanyak 1 responden $(3,22 \%)$, nyeri ringan 20 responden $(64,54 \%)$, dan nyeri sedang 10 responden $(32,26 \%)$.

3. Analisa pengaruh senam lansia terhadap perubahan nyeri sendi pada lansia yaitu ada pengaruh senam lansia terhadap perubahan nyeri sendi dilihat dari perhitungan statistic diperoleh nilai $\mathrm{p}$ value $=0,000$ yang berarti nilai $p$ value lebih kecil dari nilai alpha $(\mathrm{p}<\alpha)$ dengan $\alpha=0,05$ yang artinya Ho ditolak dan Ha diterima, yang berarti ada pengaruh senam lansia terhadap perubahan nyeri sendi pada lansia.

\section{SARAN}

Bagi responden diharapkan kepada lansia untuk selalu bersemangat untuk mengikuti kegiatan yang sudah dijadwalkan dilingkungan panti sosial khususnya senam lansia, sehingga dengan lansia rutin melakukan gerakan-gerakan senam dengan baik dan rutin dapat mengurangi nyeri sendi yg dirasakan. 


\section{DAFTAR PUSTAKA}

Anggriyana dan Atikah. 2010. Senam Kesehatan. Yogyakarta : NuhaMedica.

Arikunto, S. 2013. Prosedur Penelitian Suatu Pendekatan Praktik. Jakarata: Rineka Cipta

Handono, S. 2013. Upaya Menurunkan Keluhan Nyeri Sendi Lutut Pada Lansia diPosyandu Lansia Sejahtera (Volume 6,No.1). Jurnal Stikes RS Baptis Kediri

LeMone, P, Burke, Karen, 2008, Medical Surgical Nursing, Critical Thinking inClient Care (4th Edition), New Jersey: Prentice Hall Health

Maryam, R. Siti, dkk. 2008. Mengenal Usia Lanjut dan Perawatannya. Jakarta: SalembaMedika.

Mentes, J.C., \& Egan, B.A. 2010. Benefits of physical activity for knee osteoarthritis: A brief review. Journal Of Gerontological Nursing.

Michael, L.T., \& Kelley, T. 2010. Nonsurgical management of osteoarthritis of the knee. Journal of the American Academy of Physician Assistants

Potter, P. A; dan Perry, A, G. 2005.Buku Ajar Fundamental Keperawatan :Konsep, Proses dan Praktik. Edisi 4 Volume 1.Jakarta : EGC

Stanley dan Beare. 2007. Buku Ajar Keperawatan Gerontik. Jakarta : EGC.

Sudoyo W Aru, dkk. 2006. Buku Ajar Ilmu Penyakit Dalam. Jakarta : Pusat Penerbitan Departemen Ilmu Penyakit Dalam Fakultas Kedokteran Universitas Indonesia

Sugiyono. 2016. Statistika untuk Penelitian. Bandung: Alpabeta

Widianti, A.T. \& Proverawati, A. 2010. Senam Kesehatan. Yogyakarta: Nuha Medika. 